\title{
Real Time Multi-hop Routing Protocol for Healthcare System Based on WSN
}

\author{
Wan-Young Chung, Seong-Mo An and Seung-Chul Lee \\ Department of Electronic Engineering, Pukyong National University, Busan, South Korea \\ wychung@pknu.ac.kr
}

\begin{abstract}
:
Wireless sensor networks are networks of large numbers of sensor nodes that have sensing, communication, and processing capabilities. Recently wireless sensor network (WSN) has been widely used in quite numerous application areas. In the various application fields of WSN, the most important technology we have to focus on in health application is the transmission reliability of the health data in multi-hop communication. The loss of short term health signal can be fatal life threatening. In this paper, our research is focused on the finding of optimized routing protocol for the health related mixed data of wave-like health signals, such as ECG, PPG and linear health signal, such as body temperature and blood pressure. The reliable minimum cost routing protocol developed in our experiment shows very low wireless data packet, and shows high reliable mixed signal transmission in multi-hop communication.
\end{abstract}

Key words: Healthcare, wireless sensor network, routing protocol, biomedical engineering, ECG

\section{Introduction}

The elderly population, that is, those aged 65 years and over, currently comprises around 10 percent of the world's population, and this figure is projected to increase to 22 percent by the year 2050 [1]. Together with a concomitant socio-economic transition, this demographic shift has been forcing policy makers to prepare for the challenges of a rapidly aging society.

Providing patients with convenient health facilities at a low cost has always been a great challenge for health service providers. Moreover, the fast changing life style of the modern world and the problem of aging society pose an urgent need to modernize such facilities. This involves devising cheaper and smarter ways of providing healthcare to sufferers of age-related diseases. This paper presents a ubiquitous healthcare system for the continuous monitoring of patients under their natural physiological states or elderly persons with chronic diseases. Especially our system is designed for homecare or the monitoring of the elderly who live in country side or small rest home without enough support from caregivers or doctors, instead of patient monitoring in big hospital environment. Further insights into the natural cause and progression of diseases are afforded by context-aware sensing, which includes the use of accelerometers to monitor patient activities, or by location-aware indoor tracking based on ultrasonic and RF sensing. Moreover, our research is focused on the finding of optimized routing protocol for the wave-like health signals, such as ECG, PPG etc. The fast link exchange minimum cost routing protocol developed in our experiment shows very low wireless data packet, and shows high reliable wave-like signal transmission in multi-hop communication.

\section{System architecture}

Fig. 1 shows the conceptual system architecture of the designed wireless sensor network (WSN) based u-healthcare system which is composed of relay nodes on ceiling and mobile node. The patient or elderly wearing bio-shirt with an attached mobile node may go out of limited communication range of WSN. In order to ensure quality of biomedical signal transmission through multi-hop communication between mobile node and base station, relay nodes have to be deployed sufficiently at fixed locations on the ceiling of indoor environment for the data hand over. These relay nodes take a role of transmission of biomedical signals from a mobile node to gateway through multihop network. Relay node has only routing 
capability to transfer physiological signals, such as ECG, PPG, body temperature and other biomedical signals to the base station or to surrounding other relay nodes.

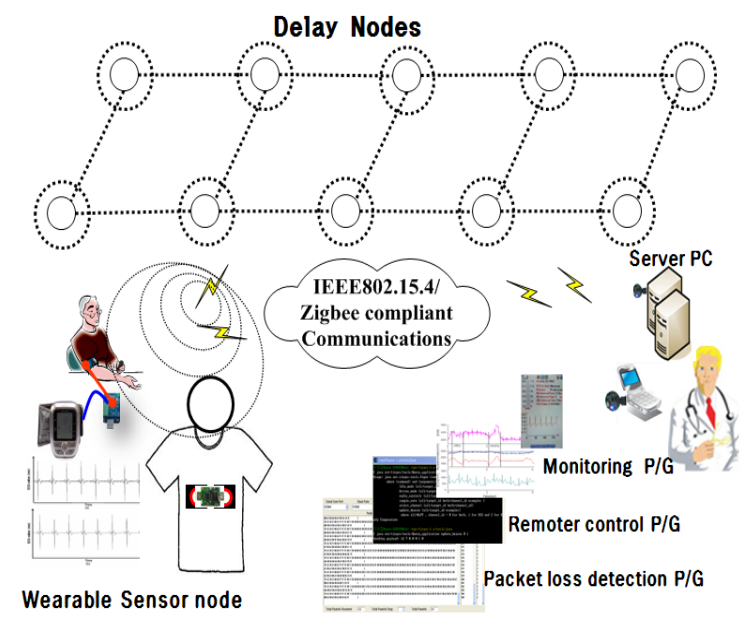

Fig.1 System architecture of u-healthcare system in WSN.

\section{Routing protocol in WSN}

(1) Wireless communication in healthcare

Until now, wireless network and wireless sensor network technologies have been widely used for the remote home healthcare, mobile healthcare, remote care for residents in island. In table 1 , the recent healthcare projects are summarized in accordance with the key technology of wireless or wireless sensor network. Here the wireless technology is the communication between two nodes, however the wireless sensor network technology is the communication between many deployed sensors with multi-hop communication.

Bluetooth module is normally used for the wireless communication between two nodes, and IEEE 802.15.4 standard is used for the WSN.

\section{(2) Wireless sensor network in healthcare}

Wireless sensor networks are networks of large numbers of sensor nodes that have sensing, communication, and processing capabilities. Sensor nodes in health monitoring are typically wore in the form of chest belt, wearable shirts, wrist belt, bio patch, and buckle like belt with the biomedical sensors on it. And the sensing data are transmitted through other sensor nodes or relay nodes to the base station. A base station may be a fixed or mobile node capable of connecting the sensor network to an existing communication infrastructure or to the internet where a user can access to the reported data. As sensor signals are acquired, it is desirable to find the best route to pass the information to the base station. There have been various routing protocols developed for the various applications in wireless sensor networks. [2-4]

Table 1 Medical Status Monitoring in Healthcare Projects

\begin{tabular}{|c|c|c|c|c|c|}
\hline \multirow{2}{*}{ Project } & HW & \multirow{2}{*}{$\begin{array}{l}\text { Sensing } \\
\text { modality }\end{array}$} & \multirow{2}{*}{$\begin{array}{c}\text { Wireless } \\
\text { or } \\
\text { WSN }\end{array}$} & \multirow{2}{*}{ Obtrusive } & \multirow{2}{*}{$\begin{array}{c}\text { Wireless } \\
\text { Tech. }\end{array}$} \\
\hline & Design & & & & \\
\hline $\begin{array}{l}\text { Mobi } \\
\text { Health }\end{array}$ & No & Multi & W & Medium & Bluetooth. \\
\hline $\begin{array}{l}\text { Code } \\
\text { Blue }\end{array}$ & Yes & Multi & WSN & High & IEEE802.15.4 \\
\hline $\begin{array}{c}\text { Alarm } \\
\text { Net }\end{array}$ & No & Multi & WSN & Medium & IEEE802.15.4 \\
\hline $\begin{array}{l}\text { Life } \\
\text { Guard }\end{array}$ & Yes & Multi & W & High & Bluetooth \\
\hline PATHS & Yes & Multi & W & High & Bluetooth \\
\hline $\begin{array}{c}\text { AWAREN } \\
\text { ESS }\end{array}$ & No & Yes & W & Single & Bluetooth \\
\hline $\begin{array}{c}\text { USN } \\
\text { LAB(Bi } \\
\text { direction } \\
\text { MCF) }\end{array}$ & YES & Mulli & WSN & High & IEEE802.15.4 \\
\hline
\end{tabular}

Sensor nodes are scattered densely in a field. Special multi-hop wireless routing protocols between the sensor nodes and the sink node are needed. As sensor signals are acquired, it is desirable to find the best route to pass the information to the destination. There have been various powerful routing protocols.

Routing protocols for sensor networks can be classified as either cluster-based hierarchical or flat. Table 2 summarizes the existing routing protocols. Data reporting in WSN is applicationdependent and also depends on the time criticality of the data. Data reporting can be categorized as either time-driven, event-driven, query-driven or a hybrid of all these methods. As such, sensor nodes will periodically switch on their sensors and transmitters, sense the environment, and transmit the data of interest at constant periodic time intervals. In event-driven and query-driven methods, sensor nodes react immediately to sudden and drastic changes in the value of a sensed attribute due to the occurrence of a certain event, or respond to a query generated by the base station or another node in the network.[5] Since energy supplies are limited communication among nodes must be both network and energy efficient. To 
prolong the network lifetime, routing protocols for wireless sensor networks in healthcare environments must support both periodic basis continuous monitoring and event-driven monitoring.

Table 2 Comparison of Existing WSN Routing Protocols

\begin{tabular}{|c|c|c|c|c|}
\hline $\begin{array}{c}\text { Routing } \\
\text { Protocol }\end{array}$ & $\begin{array}{c}\text { Network } \\
\text { Structure }\end{array}$ & Mobility & $\begin{array}{c}\text { Power } \\
\text { Consumption }\end{array}$ & $\begin{array}{c}\text { Nodes } \\
\text { extension }\end{array}$ \\
\hline Flooding & Flat & Limited & very limited & $\begin{array}{c}\text { very } \\
\text { limited }\end{array}$ \\
\hline $\begin{array}{c}\text { Directed } \\
\text { Diffusion }\end{array}$ & Proactive/flat & Limited & Limited & Limited \\
\hline $\begin{array}{c}\text { Rumor } \\
\text { Routing }\end{array}$ & Hybrid/flat & $\begin{array}{c}\text { very } \\
\text { limited }\end{array}$ & N/A & Good \\
\hline LEACH & $\begin{array}{c}\text { Reactive/ } \\
\text { hierarchical }\end{array}$ & Fixed BS & Maximum & Good \\
\hline TEEN & $\begin{array}{c}\text { Reactive/ } \\
\text { hierarchical }\end{array}$ & Fixed BS & Maximum & Good \\
\hline APTEEN & $\begin{array}{c}\text { hybrid/ } \\
\text { hierarchical }\end{array}$ & Fixed BS & Maximum & Good \\
\hline MCF & $\begin{array}{c}\text { Proactive/ } \\
\text { flat }\end{array}$ & No & N/A & Good \\
\hline
\end{tabular}

\section{(3) Wireless communication in healthcare}

Generally speaking, the primary objective of a wireless sensor network is to maximize the node/network lifetime, while performance metrics are secondary objectives. On the other hand, the main aim of a wireless healthcare system should be reliable data transfer with minimum delay.

In a healthcare network, different sensors acquire and transmit data at different sampling rates, subject to different quality of service constraints. Due to this multiple data delivery model, traditional methods of data aggregation cannot be applied to healthcare networks. Nor are energy-saving techniques that use data compression. This type of heterogeneous environment makes data routing more of challenge. Also scalability is a major issue, because single gateway architecture is not scaleable for a large set of sensors.

The time-driven delivery method is suitable for applications that require periodic data monitoring. However the routing path in our wireless sensor network field is optimized automatically in the self-organizing network by the OS programming in each wireless sensor nodes of the field server.,
Table 3 Routing protocols used in healthcare

\begin{tabular}{|c|c|c|c|c|c|}
\hline $\begin{array}{c}\text { Routing } \\
\text { Protocol }\end{array}$ & $\begin{array}{c}\text { Size } \\
\text { (nodes) }\end{array}$ & Topology & $\begin{array}{c}\text { Data } \\
\text { amount }\end{array}$ & $\begin{array}{c}\text { Data } \\
\text { delivery } \\
\text { model }\end{array}$ & Project \\
\hline LEACH & 100 & $\begin{array}{c}\text { Cluster- } \\
\text { head }\end{array}$ & Max. & Continuous & $\begin{array}{c}\text { Artificial } \\
\text { Retina }\end{array}$ \\
\hline $\begin{array}{c}\text { GBR, } \\
\text { SAR }\end{array}$ & $10-20$ & Star & Mod. & Periodic & $\begin{array}{c}\text { Vital } \\
\text { sign }\end{array}$ \\
\hline $\begin{array}{c}\text { APTEEN, } \\
\text { GEAR }\end{array}$ & $20-100$ & $\begin{array}{c}\text { Three- } \\
\text { Tiered }\end{array}$ & Large & Hybrid & $\begin{array}{c}\text { Aware } \\
\text { home }\end{array}$ \\
\hline $\begin{array}{c}\text { Flooding } \\
\text { MCF }\end{array}$ & $10-100$ & Star & Max. & Continuously & $\begin{array}{c}\text { UH- } \\
\text { PKNU }\end{array}$ \\
\hline Star & Max. & Continuously & $\begin{array}{c}\text { UH- } \\
\text { PKNU }\end{array}$ \\
\hline
\end{tabular}

In Table 3, several routing protocols which were used in the healthcare projects are listed.

\section{Routing protocol in test}

Special properties of healthcare data, including waveform data and linear data simultaneously from sensors, are considered when the system architecture including routing protocol was designed. Also the effect of packet size and routing update time on the reliability of wireless data transfer has been carefully researched.

We tested three routing protocols such as flooding, bi-directional MCF (minimum cost frotocol) and LEACH protocols to find optimal routing protocols for $\mathrm{u}$-healthcare applications [6].

In the seven serial hop communication environment like in Fig. 2, ECG signal was sent from node 7 . The packet reception ratios were compared at the node 1 after the 7 hop communication from node 7 to node 1 by the above three routing protocols such as flooding, bi-directional and MCF protocols. From the experiments, bi-directional MCF protocol shows best wireless packet reception ratio of 96.5 $\%$.This experimental result shows that the developed bi-directional MCF routing protocol is very reliable protocol for the hybrid healthcare data.

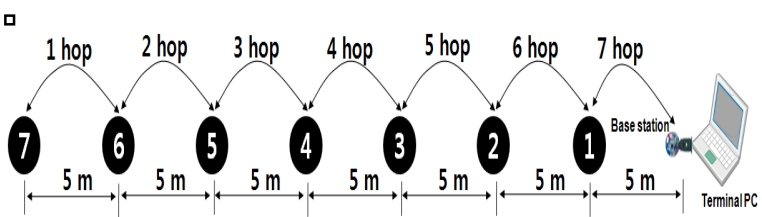

Fig.2 Experimental set-up for multi-hop communication. 


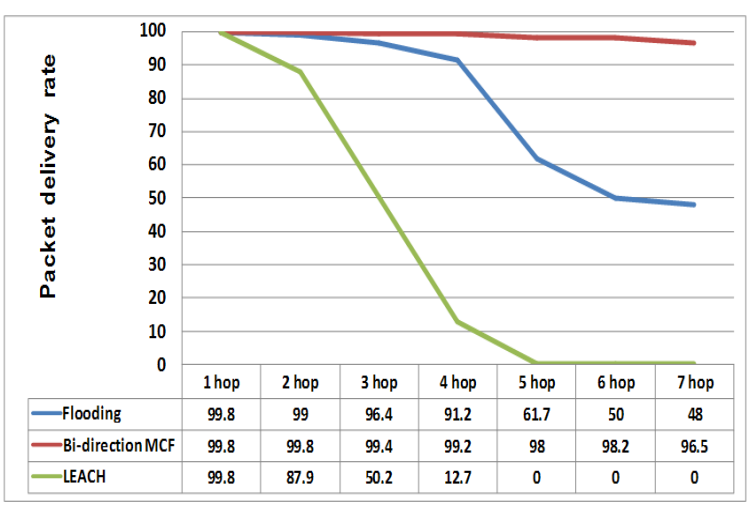

Fig.3 Packet reception ratio for different routing protocols.

\section{Conclusions}

Many routing protocols have been designed and used in various wireless sensor network applications such as environment monitoring, health monitoring, location monitoring and etc.. As healthcare applications commonly handle several types of waveform data, the application of wireless sensor network technology to uhealthcare is rather more demanding than its application to other real-time systems monitoring such factors as temperature, humidity, acoustics, light and pollution. Among three different routing protocols such as flooding, bi-directional MCF and LEACH protocols, bi-directional MCF protocol shows best reliable multi-hop communication.

\section{Acknowledgments}

The research was financially supported by the Ministry of Education, Science Technology (MEST) and National Research Foundation of Korea (NRF) through the Human Resource Training Project for Regional Innovation.

\section{References}

[1] Report of an expert group meeting population aging and development, "Social, health and gender issues with a focus on the poor in old age 29-31", Valletta, Malta.

[2] D. Yupho and J. Kabara, "Continuous vs. event driven routing protocols for WSNs in healthcare environments", Proceedings of IEEE International Conference on pervasive healthcare, 1-4 (2006).

[3] S.-H. Yang and K.-T. Song, "An adaptive routing protocol for health monitoring with a sensor network and mobile robot", Proceedings of annual conference on IEEE industrial electronics society, 2187-2192 (2010).

[4] E. E. Egbogah and A. O. Fapojuwo, "A survey of system architecture requirements for healthcarebased wireless sensor network, Sensors 11, 4875-4898 (2011).

[5] J. N. Al-Karaki, A. E. Kamal, "Routing techniques in wireless sensor networks: A survey", IEEE wireless communications, 6-28 (2004).

[6] S.-C. Lee, Ph.D. thesis, Pukyong National University, Korea (2011). 